\title{
Introduction to the Special Issue in Honor of André G. Journel
}

\author{
J. Jaime Gómez-Hernández ${ }^{1}$ • R. Mohan Srivastava ${ }^{2}$
}

Published online: 29 January 2021

(C) International Association for Mathematical Geosciences 2021

André G. Journel is the father of modern geostatistics, the geostatistics that has been fueled by modern computers and stands on stochastic simulation as its most powerful tool. He graduated from the "École Nationale Supérieure de Mines" in Nancy while at the Fontainebleau "Centre de Géostatistique" (then known as the "Centre de Morphologie Mathématique") with a dissertation on the turning-bands method of conditional simulation. While at Fontainebleau, he co-authored the first comprehensive reference book on geostatistics, which was published in 1978 as "Mining Geostatistics." That same year, he joined the now extinct Department of Applied Earth Sciences at Stanford University, where he remained until his retirement in 2012, at which time he had a joint appointment with the Departments of Geology and Environmental Sciences, and Petroleum Engineering. During his Stanford years, André built one of the world's preeminent geostatistics programs and created the Stanford Center for Reservoir Forecasting, which has served as a powerful technology transfer instrument between academia and industry. The rest of this introduction tries to give you a glimpse of what André has meant as a researcher and professor to those of us who had him as an advisor, initially regarded as a curse because he was a very demanding advisor, but soon thereafter regarded as the luckiest possible start in our careers, for he was a true mentor. It also discusses his many contributions to the world of mathematical geosciences at large, and contextualizes the papers that follow.

\footnotetext{
$凶 \quad$ J. Jaime Gómez-Hernández jgomez@upv.es

1 Institute of Water and Environmental Engineering, Universitat Politècnica de València, Camino de Vera s/n, 46022 Valencia, Spain

2 Tristar Gold Inc., Vancouver, Canada
} 


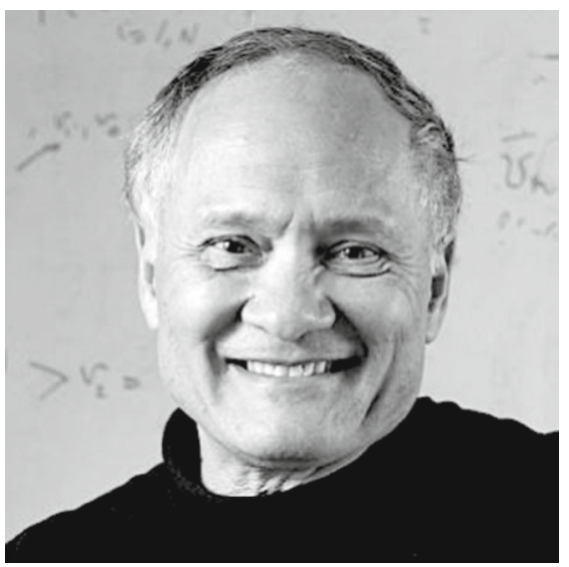

André G. Journel at his Stanford University office in 2020

Half a century ago, a young man in France pondered the "what next?" question that torments many twenty-somethings. With his military service just completed, he would now be regarded as an adult and would be expected to make well-considered decisions as he embarked on an adult life framed by a career. Unfortunately, this young man ... this André ... had too many passions, and those passions often clashed with one another. At the same time that he had a refined taste for food and wine, he also relished the planet's wild places: its deserts and mountains. He was comfortable with mathematical theory, at ease in the structure provided by lemmas, formulas and proofs; but he was equally at home writing poetry, where there is no formalism that suggests the next line, or even the next word. Of the many paths open to him, he chose to join the young "Centre de Morphologie Mathématique" in Fontainebleau ...

... and the world of mathematical geosciences is the beneficiary of that choice.

Fifty years later, the not-so-young André enjoys his small oasis in Sunnyvale, California: the pool, the jacuzzi, the garden and the house where he and Sylvie raised three fine girls: Chloe, Coraline and Sydnée, and where countless barbecue parties preceded by intense brainstorming sessions with his Ph.D. students took place. His girls are now women, and they take turns keeping André humble and happily housebound. He enjoys being a grandfather, and relishes his active role in raising his grandsons.

The pages of this Special Issue bring together just a few of the many ideas that André Journel pioneered and promoted. Even if it extended to a multi-volume set to try to do justice to all of his intellectual contributions, this collection would still be incomplete, because it could not encompass the entirety of what he has accomplished. More than being a researcher, André has been a teacher and mentor to an entire generation of geostatisticians. Among those who will soon be new professors are many Ph.D. students who were taught by professors who were taught by professors who were taught by André. His academic great-grandchildren now number in the many hundreds.

And if we somehow recorded every one of the people whose education he has influenced, we would still be missing an account of the software, now widely used, that exists because André understood the importance of having accessible computer code that transforms the ivory tower's theories into practical tools that get the job 
done in a muddy-boots world. Never shy about tracking mud into the hallways of academia, or dragging brightly polished theoretical baubles out into the field, André was constantly bridging the gap between theory and practice. He understood that algorithms are not merely recipes that encode theory, but that they actually inform and enrich theory.

And even if we somehow indexed the millions of lines of code that trace their lineage back to one of André's software initiatives, we would still be missing the essence of the man who charmed as many people as he infuriated. The one who would say things so odd that one never knew if he was trying to be provocative for a reason, was trying to be entertaining, was simply confused or was just plain mad. At one of the early meetings of the Stanford Center for Reservoir Forecasting, he told his industrial affiliates consortium that they should never contour permeability. As people protested this absurd statement, he stuck to his guns and insisted that it made no sense to render a fundamentally discontinuous attribute in a visual format that encouraged the belief that it was continuous. Madness. But today's norm is exactly the alternative that André promoted that day: color pixel maps or colored point clouds.

There have certainly been many times when he fully embraced his role as entertainer, like when he would stumble around with his eyes closed, pretending to explore the classroom with only two fingers to emphasize the poverty of a two-point summary statistic, the variogram. Students of his, now approaching retirement, still recall the twinkle in his eye when he was about to use one of his oft-repeated sayings ... "we are eagles, we are not moles," "there is no free lunch" ... or when he started to rant about the "the Gaussian Disease." There was method in his madness as a performer and entertainer. He understood that ideas don't prevail on their merits alone; they need to be wrapped up in a memorable moment, and promoted.

And it's in his lifetime of provocation that André has arguably made the greatest contribution. He didn't just come up with important new ideas. He didn't just teach students and mentor them through their own research. He didn't just equip the world with geostatistical software tools. More than any of that, he provoked. He challenged his peers, his supporters and his detractors to think differently, and to see the links between ideas in different disciplines.

Since retiring from Stanford University, he has done a remarkable job of honoring his commitment to focus on being a husband, a father and a grandfather. He did not keep an office at the university; he did not advise students or teach special lectures; he left all of that behind so that he could focus his passion and energy on other important things ... more important things: family and poetry. But on the whiteboard in his personal office at home one could still see, at least through the summer of 2019, the very last piece of geostatistical theory he contemplated, something he chose not to erase for many years, presumably because he liked to ponder it from time to time. 


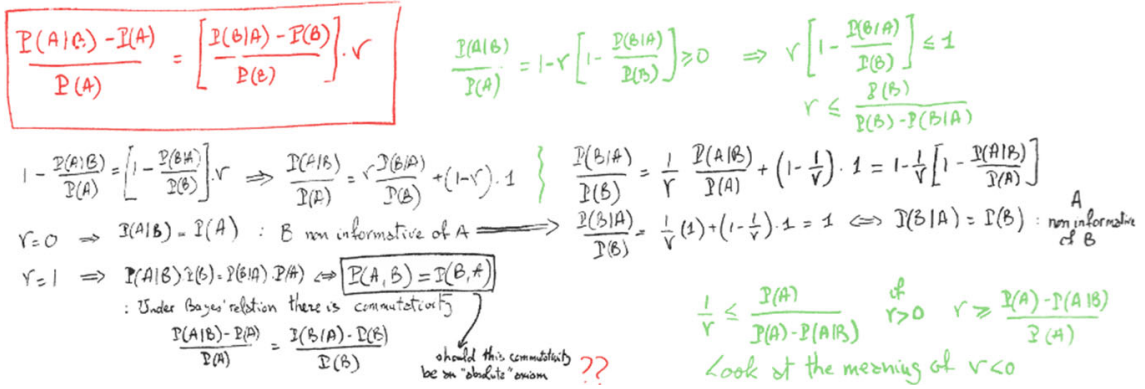

The whiteboard in André Journel's Sunnyvale office, July 2019.

In the equations and notation on that whiteboard, one sees a mind that loved to turn things on their side and then on their head by assuming that something you believed to be true might actually be false. He enjoyed following the consequence of heretical thoughts, wherever they might lead. His last hike into the unmapped wilderness of geostatistical theory was one of those bits of vintage André madness: what if Bayes' Theorem is not universally true? Recognizing it as a statement about the commutativity of conditional probabilities, he wanted to explore the possibility that the commutativity might not hold true in certain cases. Like the explorer-navigators of old, André was never afraid to sail right off the edge.

The papers collected in this Special Issue are no more than a snapshot of some of the methods that André seeded and nurtured. In years to come, some of the other seeds he planted may flourish and rival the importance of the topics covered in this Special Issue. But at this moment, half a century after young André chose geostatistics over poetry, many readers will recognize that these papers cover a wide swath of the Mathematical Geosciences universe.

As the reader goes through the papers in this special issue, the distinctive feeling that they have been written by former students or colleagues permeates in a manner that is not common in academic journals. A few concessions have been made and, without departing from the rigor requested of all scholarly articles, authors have been allowed to include some personal statements reflecting their relationship with André.

This collection of papers begins with One Step at a Time: The Origins of Sequential Simulation and Beyond, by J. Jaime Gómez-Hernández and R. Mohan Srivastava, students of André Journel during the 1980s. Of the many new methods developed at Stanford University during this decade, the sequential approach to simulation has become the most deeply rooted and widespread. Almost every commercial software package that offers conditional simulation includes a sequential algorithm, and many of them offer only sequential simulation.

In Geostatistical Seismic Inversion: One Nugget from the Tróia Conference, Amilcar Soares, one of André's first students at Stanford, takes a look at the use of geostatistics in "inverse problems" that are common with methods that probe an object by passing energy through it and measuring properties of the energy as it passes through the object, is attenuated, refracted and reflected. Geophysical seismic surveys are one of the most common earth-science studies that give rise to inverse problems, and methods developed by André, his students and his colleagues at the Stanford Center for Reservoir Forecasting continue to be adapted, improved and widely used in the 
petroleum industry. Close cousins of these methods also have been used in groundwater hydrology, in medical imaging using tomography, and in image enhancement and reconstruction.

Throughout his career, André Journel maintained a consistent vision for how decision-making should be done in earth sciences, beginning with quantifying uncertainty (never fooling yourself into believing in a single unique estimate, even if it carried the label "best") and then using that knowledge of uncertainty to make riskqualified decisions. His writings and research on "risk-qualified mapping" began in the 1980s when he became involved in research on contaminated site remediation studies with the U.S. Environmental Protection Agency. He was a driving force behind the development of Geo-EAS, a public-domain software that put geostatistical tools in the hands of practitioners. In Implementation of Geostatistical Algorithms, Clayton Deutsch, a student and former faculty colleague at Stanford, discusses André's recognition that public and freely available software toolkits were necessary for realizing the vision of risk-qualified decision-making. The Geo-EAS project from the 1980s inspired the GSLIB project spearheaded by Clayton Deutsch in the 1990s, and SGeMS, led by Nicolas Remy, Alexandre Boucher and Jianbing Wu in the 2000s. Through four decades, beginning with the Fortran code in Mining Geostatistics, André Journel has made sure that the world was equipped not only with theoretical ideas, but also with practical tools.

One of the remarkable things about André's contributions ... one of the many remarkable things ... is the breadth of applications of ideas and methods that he pioneered and promoted. Like the snake-oil salesman who traveled the American West in the 1800s, offering cures for whatever diseases and ailments he learned about in each new town, André has never been shy about offering new solutions to problems he only recently learned about. Though mining, petroleum and environmental applications remain the main application areas of geostatistics, André's brand of geostatistical elixir has been used in social sciences, in crop studies, in climate change research, in medical imaging, in criminal forensics, geotechnical studies ... on and on it goes. In From Natural Resources Evaluation to Environmental Epidemiology: 25 Years in the Making, Pierre Goovaerts, a post-doctoral researcher at Stanford in the 1990s, describes how ideas from successful geostatistics applications in other fields, like agronomy, were adapted and refined for use in epidemiology, where "space" is no longer the Euclidean space that governs many subsurface applications, but the social space and inter-distances that signify in studies of health and the spread of disease.

In addition to having huge intellectual breadth, André's research legacy also shows exceptional depth. He has never been shy about asking "why?", and then asking "why?" again, running the questions right to the bottom of the tree of knowledge, and questioning the roots and bedrock. A quarter-century after he learned and mastered the foundations of "classical" geostatistics, with its two-point variograms, he pushed forward the idea that geostatistics should move beyond two-point statistics and into the realm of multi-point statistics, culminating in the Ph.D. thesis of Sebastien Strebelle. In MPS models: Pretty Pictures or Decision-Making Tools?, Sebastien reviews the evolution of the MPS idea and its rapid acceptance as a simulation algorithm that is not only practically feasible but also capable of replicating spatial patterns beyond the reach of two-point algorithms. At the core of the MPS idea are a couple of foundation- 
shaking ideas that have, through thousands of case studies and dozens of software implementations, opened up entire new avenues of research in spatial simulation: the idea that a variogram model can be replaced with a training image from which statistical parameters are drawn directly; and the idea that a random function and its space of uncertainty does not need to be expressed mathematically but can, instead, be expressed in the form of an algorithm and the realizations it is capable of producing.

In Conditional Simulation for Mineral Resource Classification and Mining Dilution Assessment from the early 1990s to Now, Georges Verly, another of André's first students at Stanford, and Harry Parker write about the use of conditional simulation in the mining industry. André's Ph.D. thesis in the early 1970s was on the turning bands method of conditional simulation; and his undergraduate degree was in mining engineering. Though slow to be adopted in the mining industry, conditional simulation has become the gold standard for certain types of mine planning studies. The importance of André's contributions to the mining industry can be measured by the fact that Harry Parker's work on his contribution to this Special Issue was completed from his hospital bed. Harry Parker, himself a pioneer and giant in mining geostatistics, passed away in December 2019. Harry was instrumental in arranging a half-time Visiting Professor position at Stanford in 1978 that brought André to the United States from France, and in supplementing the Stanford position with a half-time consulting position at Fluor Mining and Metals.

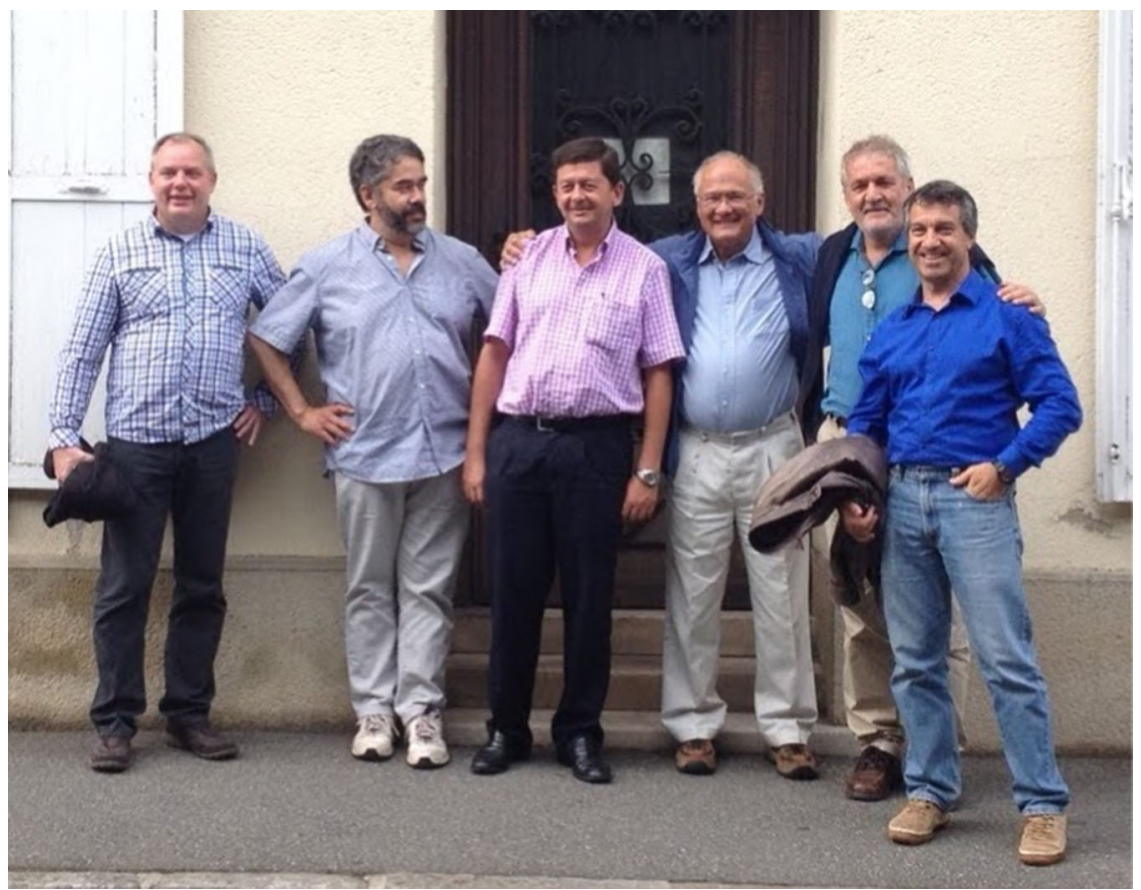

Where it all started: the "Centre de Géostatistique" at Fontainebleau. In front of the entrance door, from left to right: Clayton V. Deutsch, R. Mohan Srivastava, J. Jaime Gómez-Hernández, André G. Journel, Amilcar Soares and François Alabert, July 2014. 
We were fortunate to be the academic sons of André, and we are thankful to Editorin-Chief Roussos Dimitrakopoulos for approaching us to curate this collection of papers in honor of our mentor and, today, friend.

J. Jaime Gómez-Hernández, Valencia, Spain R. Mohan Srivastava, Toronto, Canada

With contributions from: François Alabert, Charles Huijbregts, Harry Parker and Georges Verly. 